\title{
Postglacial population growth of Cunninghamia konishii (Cupressaceae) inferred from phylogeographical and mismatch analysis of chloroplast DNA variation
}

\author{
SHIH-YING HWANG, ${ }^{*}$ TSAN-PIAO LIN,+CHIU-SHUN MA, ${ }^{*}$ CHUNG-LING LIN, \\ JENG-DER CHUNG \\ *Graduate Institute of Biotechnology, Chinese Culture University, Hwagan Road, Yangmingshan, Taipei, Taiwan 111, +National \\ Taiwan University, Department of Botany, Roosevelt Road, Section 4, Taipei, Taiwan 106, and łTaiwan Forest Research Institute, \\ Nanhai Road, Taiwan 100
}

\begin{abstract}
Phylogeographical and mismatch analysis of chloroplast DNA (cpDNA) variation were used to infer the temporal dynamics of distributional and demographic history of Taiwan fir (Cunninghamia konishii). We examined 64 and 52 trees from 17 populations of $C$. konishii and 14 provenances of $C$. lanceolata, respectively, by sequencing three intergenic spacers and one intron using cpDNA universal primers. Of the aligned 1888 base pairs (bp) sequence, 30 varied among 28 haplotypes, which consisted of three transitions, 14 transversions and 13 indels. One ancestral haplotype was found in 86 individuals across the surveyed range of both species, $C$. konishii and $C$. lanceolata, which was distributed in all populations and provenances. The 28 haplotypes also included 15 C. konishii specific and 12 C. lanceolataspecific haplotypes. Ancestral haplotype was found fixed in five populations of $C$. konishii and five provenances of $C$. lanceolata. Other haplotypes occurred mainly as singletons. The levels of population differentiation studied are relatively low in both Cunninghamia species. The nucleotide diversity $(\theta)$ of chloroplast DNA sequences within $C$. konishii was slightly higher than that of $\mathrm{C}$. lanceolata. Excess in singletons as well as star-like phylogeny of haplotypes suggested no clearcut migration patterns of $C$. konishii after glacial maximum. One probable demographic history of $C$. konishii is the postglacial population growth of $C$. konishii after a glacial bottleneck event. This inference is supported by the combined results of fossil pollen record, low nucleotide diversity, significant Tajima's $D$-value, phylogeographical analysis and unimodal mismatch distribution. Similarities and discrepancies between our results and those of $\mathrm{Lu}$ et al. (2001) are discussed.
\end{abstract}

Keywords: cpDNA, Cunninghamia konishii, postglacial population growth, Taiwan

Received 14 February 2003; revision received 22 May 2003; accepted 11 June 2003

\section{Introduction}

Temperature oscillations during ice ages of the Pleistocene forced species to move south or migrate to lower altitudes, where the environment may not be suitable for species to grow to a large population size, thus resulting in a bottleneck (Hewitt 1996). Species that survived in refugia in the south or in the lower elevations may recolonize

Correspondence: Dr Shih-Ying Hwang. Fax: 88622861 8266; E-mail: hsy9347@ms34.hinet.net habitats where plant species can grow for range expansion when climate becomes suitable in the north and at higher altitudes. Fossil pollen records as well as the present-day distribution of genetic variability can be used to trace backwards in time to know the demographic history of the species (Cruzan \& Templeton 2000). Valuable information on the evolutionary history of forest trees can be obtained through sequence data that allow assessment of the relative roles of natural selection and genetic drift on genetic variation and population differentiation (Otto 2000). Chloroplast DNA variation is a useful tool in deciphering the spatiotemporal dynamics of the organism studied because of its 
small rate of structural and sequence evolution with rare or absent recombination and uniparental inheritance (Palmer 1987; Palmer et al. 1988). The cpDNA variation has been used for phylogeny reconstruction at the population level in many plant species, e.g. European oaks (Ferris et al. 1995; Dumolin-Lapègue et al. 1997; Matyas \& Sperisen 2001), Kandelia candel (Chiang et al. 2001) and Cyclobalanopsis glauca (Huang et al. 2002).

Old growth of Cunninghamia konishii Hay. (= C. lanceolata (Lamb.) Hook. var. konishii (Hay.) Fujita) is usually found scattered within forests of Chamaecyparis, Pinus spp. and Pseudotsuga wilsoniana at elevations of 1300-2800 m (Liu 1966). C. lanceolata (Lamb.) Hook. is a species that occurs only in mainland China. Both C. konishii and C. lanceolata had high genetic diversity (Müller-Starck \& Liu 1989; Yeh et al. 1994; Lin et al. 1998) revealed by allozyme assay. These two Cunninghamia species are related closely, with very little taxic differentiation according to allozyme data (Lin et al. 1998).

The lowland vegetation was dominated by cooltemperate forest composed of conifers mixed with deciduous hardwood species around $745.5 \mathrm{~m}$ altitude during the last glacial maximum according to fossil pollen evidence from Jih-Yueh Tan $\left(23^{\circ} 49^{\prime} \mathrm{N} ; 120^{\circ} 53^{\prime} \mathrm{N}\right)$ in central Taiwan (Tsukada 1967). The evidence of palaeontology indicated a once-downward migration of C. konishii during glacial maximum from higher altitude. Events of recolonization of higher altitude after glacial maximum are possible. Values of population differentiation for C. lanceolata and C. konishii, as estimated by Yeh et al. (1994) and Lin et al. (1998) using allozymes, are low and fall within the range observed typically for species with long generation times and high outcrossing rates, such as conifers (Hamrick et al. 1992). Another factor affecting the present-day distribution of genetic variation may be the rate at which C. konishii recolonized at higher altitudes.

In the present study, nucleotide diversity analysis of four chloroplast noncoding sequences including trnD-trn $\mathrm{T}$, $\operatorname{trn} \mathrm{L}-\operatorname{trn} \mathrm{F}$, and petG-trn $\mathrm{P}$ intergenic spacers and $t r n \mathrm{~V}$ intron together, with phylogeographical and mismatch analysis, were used to infer the temporal dynamics of distributional and demographic history of $C$. konishii throughout its native geographical range.

\section{Materials and methods}

Sixty-four individuals of C. konishii transplanted by grafting from 17 different natural populations were collected from seed orchards at Chuyunshan, Tongsyh and from a clonal garden established in 1978 at the Lienhuachih Station, Taiwan Forestry Research Institute (TFRI), as well as from old growth of Shiyuan, Wuser and Alishan. Fiftytwo individuals of C. lanceolata originating from 44 seed sources from China (14 provenances) were also collected from Lienhuachih Station. The code names for populations and sample sizes for C. konishii and C. lanceolata are listed in Table 1 and Fig. 1.

Total DNA was extracted from ground leaf powder according to a modified cetyltrimethyl ammonium bromide (CTAB) procedure (Doyle \& Doyle 1987) and described in detail by Hwang et al. (2001). Polymerase chain reaction (PCR) amplification was achieved for trnV intron (Huang et al. 2002), trnL-trnF (Taberlet et al. 1991), trnD-trnT (Demesure et al. 1995) and petG-trnP (Hwang et al. 2000). PCR reaction conditions followed Hwang et al. (2001) with optimal annealing temperatures of $58^{\circ} \mathrm{C}$ for petG-trnP, $56{ }^{\circ} \mathrm{C}$ for $\operatorname{trn} \mathrm{L}-\operatorname{trn} \mathrm{F}, 52^{\circ} \mathrm{C}$ for $\operatorname{trn} \mathrm{D}-\operatorname{trn} \mathrm{T}$ and $60{ }^{\circ} \mathrm{C}$ for $\operatorname{trn} \mathrm{V}$ intron. The PCR mixture $(50 \mu \mathrm{L})$ contained $50 \mathrm{~mm} \mathrm{KCl}$, $1.5 \mathrm{~mm} \mathrm{MgCl}_{2}, 0.001 \%$ gelatin, $10 \mathrm{~mm}$ Tris- $\mathrm{HCl}$ ( $\mathrm{pH} 8.3$ ), $100 \mu \mathrm{M}$ of each dNTP, $0.2 \mu \mathrm{M}$ primer, $20 \mathrm{ng}$ template DNA, $1 \mu \mathrm{g}$ RNase and $0.5 \mathrm{U}$ Taq polymerase (Amersham Pharmacia Biotech). PCR products were purified and sequenced in both directions using Taq Dye Dideoxy Terminator Cycle Sequencing Kit (Applied Biosystems) and Model ABI373A automated sequencer (Applied Biosystems). All sequence polymorphisms were rechecked visually from chromatograms. Singletons were verified by resequencing.

Multiple alignments of the sequences were obtained using CLUSTAL w (Thompson et al. 1994) and subsequent manual adjustment. Haplotype diversity $(h)$, nucleotide diversity $(\theta)$ (Nei 1987), Tajima's D (Tajima 1989) as well as Fu \& Li's $D^{*}$ test (Fu \& Li 1993) for departure from neutrality on total number of segregating sites were calculated using DnaSP version 3.14 (Rozas \& Rozas 1999). We used a pairwise mismatch distribution to test for population expansion (Rogers \& Harpending 1992) by using the DnaSP program. Construction of the phylogenetic network was performed by TCs version 1.06, as described in Templeton et al. (1992). Two measures of population differentiation $\left(G_{\mathrm{ST}}\right.$ and $\left.N_{\mathrm{ST}}\right)$ were obtained according to Pons \& Petit (1996).

\section{Results}

Sequence analyses, mismatch distribution and neutrality tests

Among 30 polymorphic sites, three transitions, 14 transversions and 13 indels were detected from the aligned 1888 base pairs (bp) sequences. The examined sequences consisted of $\operatorname{trn} \mathrm{V}$ intron (472 bp, GenBank Accession nos AF549430-AF549440) and three intergenic spacers including petG-trnP (441 bp, GenBank Accession nos AF549412AF549415), trnD-trnT (664 bp, GenBank Accession nos AF549416-AAF549418) and trnL-trnF (311 bp, GenBank Accession nos AF549419-AF549429). In C. konishii, the mean nucleotide diversity is $0.00190 \pm 0.00067$, and the mean haplotype diversity is $0.463 \pm 0.079$ for 17 C. konishii populations. In contrast, for $14 \mathrm{C}$. lanceolata provenances, the mean 
Table 1 Genetic diversity within and population differentiation between populations of Cunninghamia konishii and provenances of Cunninghamia lanceolata

\begin{tabular}{|c|c|c|c|c|c|c|c|}
\hline $\begin{array}{l}\text { Population } \\
\text { (code/sample size) }\end{array}$ & $\begin{array}{l}\text { Haplotype/ } \\
\text { no. individuals }\end{array}$ & $\begin{array}{l}\text { Haplotype } \\
\text { diversity }(h)\end{array}$ & $\begin{array}{l}\text { Nucleotide } \\
\text { diversity }(\theta)\end{array}$ & $\begin{array}{l}\text { Tajima's } \\
D(P)\end{array}$ & $\begin{array}{l}\mathrm{Fu} \& \mathrm{Li}^{\prime} \mathrm{s} \\
D^{*}(P)\end{array}$ & $G_{\mathrm{ST}}$ & $N_{\mathrm{ST}}$ \\
\hline \multicolumn{8}{|l|}{ Cunninghamia konishii } \\
\hline Total & & $0.463 \pm 0.079$ & $0.00190 \pm 0.00067$ & $\begin{array}{l}-2.41047 \\
(P<0.02)\end{array}$ & $\begin{array}{l}-3.74181 \\
(P<0.001)\end{array}$ & 0.073 & 0.119 \\
\hline Tashueshan (TH/4) & A 2, KTH $1 / 1, \mathrm{KTH} 4 / 1$ & $0.833 \pm 0.222$ & $0.00116 \pm 0.00079$ & & & & \\
\hline Denta (DT/4) & $\mathrm{A} / 4$ & $0.000 \pm 0.000$ & $0.00000 \pm 0.00000$ & & & & \\
\hline Kuanwu (KW/4) & $\mathrm{A} / 3, \mathrm{KKW} 1 / 1$ & $0.500 \pm 0.265$ & $0.00087 \pm 0.00063$ & & & & \\
\hline Yenhai (YH/4) & $\mathrm{A} / 3, \mathrm{KYH} 4 / 1$ & $0.500 \pm 0.265$ & $0.00058 \pm 0.00046$ & & & & \\
\hline Tayuanshan (TY/3) & A/2, KTY3/1 & $0.667 \pm 0.314$ & $0.00035 \pm 0.00035$ & & & & \\
\hline Shengkuang (SK/4) & $\mathrm{A} / 3, \mathrm{KSK} 4 / 1$ & $0.500 \pm 0.265$ & $0.00029 \pm 0.00029$ & & & & \\
\hline Chihlehhsi (CL/1) & $\mathrm{A} / 1$ & $0.000 \pm 0.000$ & $0.00000 \pm 0.00000$ & & & & \\
\hline Shiyuan (SY/4) & $\mathrm{A} / 2, \mathrm{KSY} 1 / 2$ & $0.667 \pm 0.204$ & $0.00029 \pm 0.00029$ & & & & \\
\hline Wuser (WS/4) & $\mathrm{A} / 3, \mathrm{KWS} 3 / 1$ & $0.500 \pm 0.265$ & $0.00029 \pm 0.00029$ & & & & \\
\hline Alishan (AL/4) & A/3, KAL4/1 & $0.500 \pm 0.265$ & $0.00029 \pm 0.00029$ & & & & \\
\hline Tajiann $(\mathrm{TJ} / 4)$ & $\mathrm{A} / 1, \mathrm{KTJ} 4 / 1, \mathrm{KTJ} 2 / 1, \mathrm{KTJ} 1 / 1$ & $1.000 \pm 0.177$ & $0.00087 \pm 0.00067$ & & & & \\
\hline Shiouhluan (SL/4) & $\mathrm{A} / 4$ & $0.000 \pm 0.000$ & $0.00000 \pm 0.00000$ & & & & \\
\hline Chuyunshan (CY/4) & $\mathrm{A} / 4$ & $0.000 \pm 0.000$ & $0.00000 \pm 0.00000$ & & & & \\
\hline Kuangmingchao $(\mathrm{KM} / 4)$ & $\mathrm{A} / 4$ & $0.000 \pm 0.000$ & $0.00000 \pm 0.00000$ & & & & \\
\hline Anmashan (AM/4) & $\mathrm{A} / 3, \mathrm{KAM} 3 / 2$ & $0.500 \pm 0.265$ & $0.00029 \pm 0.00029$ & & & & \\
\hline Wulin (WL/4) & $\mathrm{A} / 3, \mathrm{KWL} 2 / 1$ & $0.500 \pm 0.265$ & $0.00058 \pm 0.00046$ & & & & \\
\hline Chitou (CT/4) & $\mathrm{A} / 2, \mathrm{KCT} 2 / 1, \mathrm{KTH} 4 / 1$ & $0.833 \pm 0.222$ & $0.00087 \pm 0.00063$ & & & & \\
\hline \multicolumn{8}{|l|}{ Cunninghamia lanceolata } \\
\hline Total & & $0.440 \pm 0.088$ & $0.00176 \pm 0.00065$ & $\begin{array}{l}-2.44968 \\
(P<0.02)\end{array}$ & $\begin{array}{l}-4.46944 \\
(P<0.02)\end{array}$ & 0.017 & 0.014 \\
\hline Yunnan (YN/4) & $\mathrm{A} / 4$ & $0.000 \pm 0.000$ & $0.00000 \pm 0.00000$ & & & & \\
\hline Jiangxi (JX/4) & $\mathrm{A} / 3, \mathrm{LJX} 3 / 1$ & $0.500 \pm 0.265$ & $0.00029 \pm 0.00029$ & & & & \\
\hline Shanxi (SX/4) & $\mathrm{A} / 2, \mathrm{LSX} 1 / 1, \mathrm{LSX} 3 / 1$ & $0.833 \pm 0.222$ & $0.00087 \pm 0.00063$ & & & & \\
\hline Anhui (AH/2) & $\mathrm{A} / 2$ & $0.000 \pm 0.000$ & $0.00000 \pm 0.00000$ & & & & \\
\hline Zhejiang (ZJ/4) & A/3, LZJ4/1 & $0.500 \pm 0.265$ & $0.00058 \pm 0.00046$ & & & & \\
\hline Hunan $(\mathrm{HN} / 4)$ & $\mathrm{A} / 3, \mathrm{LHN} 2 / 1$ & $0.500 \pm 0.265$ & $0.00029 \pm 0.00029$ & & & & \\
\hline Hubei (HB/4) & $\mathrm{A} / 4$ & $0.000 \pm 0.000$ & $0.00000 \pm 0.00000$ & & & & \\
\hline Sichuan (SC/4) & $\mathrm{A} / 3, \mathrm{LSC} 2 / 1$ & $0.500 \pm 0.265$ & $0.00029 \pm 0.00029$ & & & & \\
\hline Guizhou (GZ/4) & $\mathrm{A} / 4$ & $0.000 \pm 0.000$ & $0.00000 \pm 0.00000$ & & & & \\
\hline Fujian (FJ/4) & $\mathrm{A} / 3, \mathrm{LFJ} 4 / 1$ & $0.500 \pm 0.265$ & $0.00029 \pm 0.00029$ & & & & \\
\hline Guangdong (GD/4) & $\mathrm{A} / 2, \mathrm{LGD} 2 / 1, \mathrm{LGD} 4 / 1$ & $0.833 \pm 0.222$ & $0.00058 \pm 0.00046$ & & & & \\
\hline Guangxi $(\mathrm{GX} / 4)$ & A/2, LJS2/1, LGX3/1 & $0.833 \pm 0.222$ & $0.00087 \pm 0.00063$ & & & & \\
\hline Jiangsu (JS/4) & A/2, LJS4/1, LJS2/1 & $0.833 \pm 0.222$ & $0.00087 \pm 0.00063$ & & & & \\
\hline Henan (HE/2) & $\mathrm{A} / 2$ & $0.000 \pm 0.000$ & $0.00000 \pm 0.00000$ & & & & \\
\hline
\end{tabular}

nucleotide diversity is $0.00176 \pm 0.00065$ and the mean haplotype diversity is $0.440 \pm 0.088$. Populations of $C$. konishii from Tashueshan $(\theta=0.00116)$, Tajiann and Chitou $(\theta=0.00087)$ appeared to contain higher nucleotide diversity (Table 1). In C. lanceolata, provenances from Shanshi, Jiangshu and Guangxi $(\theta=0.00087)$ had higher nucleotide diversity (Table 1).

We identified 28 unique haplotypes using the TCs program, in which one ancestral haplotype was identified in 86 individuals for both C. konishii and C. lanceolata along with 15 haplotypes specific to C. konishii and 12 haplotypes specific to C. lanceolata. Haplotype network depicted a 'star-like' phylogeny (Fig. 2a). Nine of 15 C. konishii specific haplotypes were found in Taichung County in central
Taiwan, with four haplotypes found in population Tajiann. Haplotypes that belong to C. konishii are initialized with the letter $\mathrm{K}$, while those that belong to C. lanceolata are initialized with the letter L in Figs 1 and 2a. The ancestral allele occurs in every population of $C$. konishii and every seed source of C. lanceolata. For C. lanceolata, haplotype LJS2 occurs in both Jiangsu and Guangxi provenances and other haplotypes are observed only in one single individual and characterized as autapomorphies. Provenances of Shanxi, Guandong, Guanxi and Jiangsu housed two haplotypes each. For C. konishii, haplotypes KSY1 and KAM3 were found in two individuals each of Shiyuan and Anmashan population, respectively. Most haplotypes occur as autapomorphies in C. konishii. Haplotype KTH4 


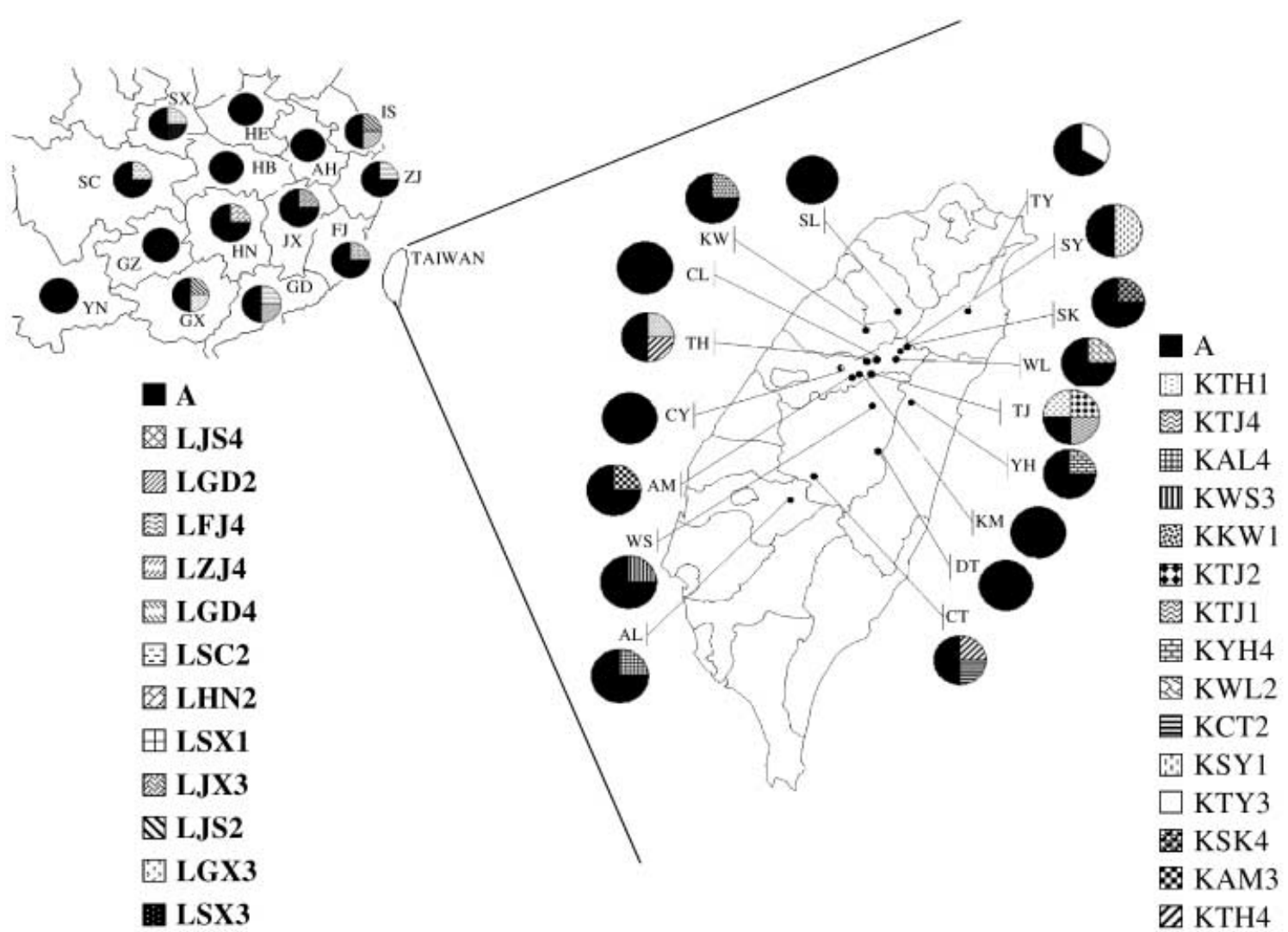

Fig. 1 Sample localities and geographical distribution of the cpDNA haplotypes of Cunninghamia konishii and C. lanceolata located in Taiwan and China.

was found in one individual each of Tashueshan and Chitou population. The significant skewness toward rare alleles in combined sequences of chloroplast $t r n \mathrm{~V}$ intron and three intergenic spacers indicating high level of singletons occur in Cunninghamia. Neutrality test by Tajima's $D(-2.41047$, $P<0.02)$ and Fu \& Li's test statistic $D^{*}(-3.74181, P<0.001)$ showed the negative values significantly different from zero, indicating an excess of rare alleles over that expected for null neutral hypothesis in an equilibrium population.

To investigate the hypothesis of population expansion in C. konishii, we computed the distribution of pairwise differences from the segregating sites of cpDNA haplotypes in C. konishii using the DnaSP program. The mismatch distribution analysed showed no significant difference from Poisson expectation (Kolmogorov-Smirnoff test, $Z=1.800$, $P=0.4682)$ and a unimodal mismatch distribution was observed based on the infinite-sites predictions and mutation rate homogeneity. The Harpending's raggedness index $r=0.0432$ (Harpending 1994), indicating a smooth distribution, reflected a model of sudden expansion (Fig. 2b) in contrast to a constant population model. Because C. lanceolata has been cultivated for more than 2000 years (Chen \& Shi 1983), exchange of seed sources might have confounded the explanation of demographic history; therefore, we will not attempt to make inference for the demographic history of C. lanceolata.

\section{Analyses of population structure}

Population differentiation according to frequencies and the degree of haplotype divergence of the 17 populations in C. konishii in Taiwan was 0.073 and 0.119 for $G_{\mathrm{ST}}$ and $N_{\mathrm{ST}}$, respectively (Table 1 ). The $G_{\mathrm{ST}}$ and $N_{\mathrm{ST}}$ was 0.017 and 0.014 for 14 provenances in C. lanceolata (Table 1). The result indicated a low degree of genetic structure of cpDNA variations.

\section{Discussion}

\section{Haplotype diversity and relationships}

Fourteen of 15 haplotypes (93\%) may be considered population-specific, as they are found uniquely in one stand only in C. konishii. The characteristic of population-specific haplotype is a general peculiarity in conifer species as described by Vendramin et al. (2000). One of the C. lanceolata haplotype, LGD2, gave rise to haplotypes LJS4, KKW1 and KTJ2. No reverse situation was found in which a C. konishii haplotype was ancestral to a C. lanceolata haplotype. This 


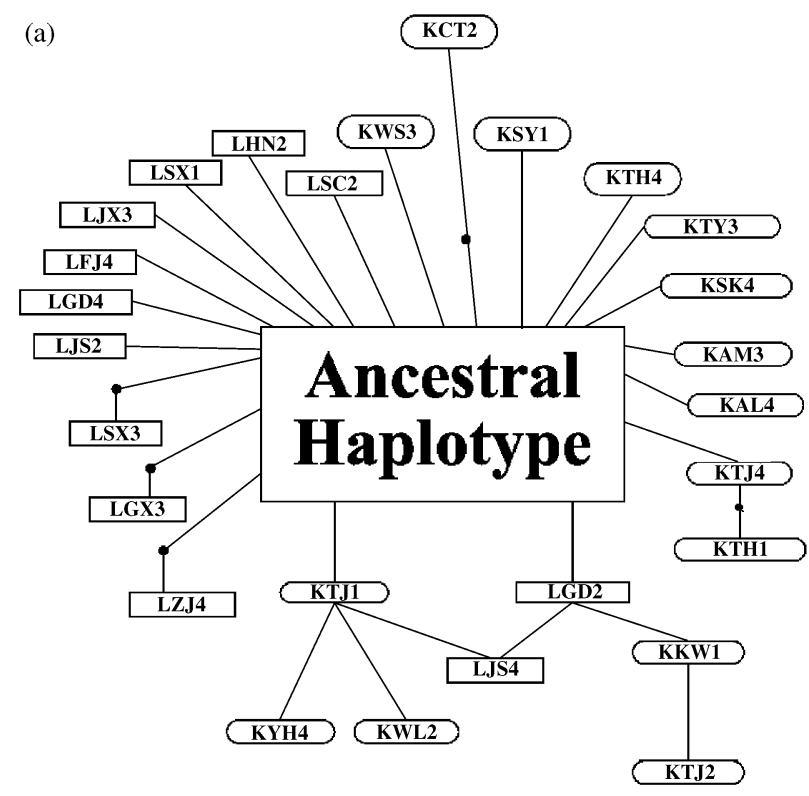

(b)

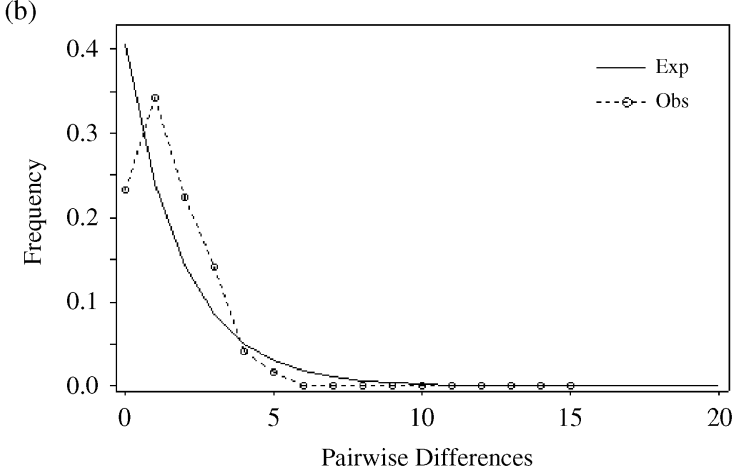

Fig. 2 (a) The star-like phylogenetic network depicting the haplotype relationships of Cunninghamia konishii and C. lanceolata based on $\operatorname{trn} \mathrm{V}$ intron, petG-trnP, $\operatorname{trn} \mathrm{L}-\operatorname{trn} \mathrm{F}$ and $\operatorname{trn} \mathrm{D}-\operatorname{trn} \mathrm{T}$ intergenic spacers of the chloroplast DNA. Each line between haplotypes represents a mutational step; the dotted line represents another mutational step between haplotypes. TCs software was used in this analysis. (b) Mismatch distribution established for Cunninghamia konishii; the thin line represents the expected mismatch distribution of a stationary population. The dotted line represents the observed mismatch distribution from segregating

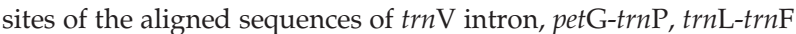
and $\operatorname{trn} \mathrm{D}-\operatorname{trn} \mathrm{T}$ intergenic spacers of the chloroplast DNA in Cunninghamia konishii.

reveals that some C. konishii haplotypes are derived $C$. lanceolata haplotypes. We therefore hypothesize that Kuanwu, and especially the population Tajiann, was the site where C. lanceolata recolonized Taiwan from mainland China.

\section{Population structure}

In this study, low levels of population differentiation in both Cunninghamia species is consistent with the paternal inheritance in cpDNA of conifers (Vendramin et al. 1999; Bucci \& Vendramin 2000; Vendramin et al. 2000; Ribeiro et al. 2002; Richardson et al. 2002). Lu et al. (2001) suggested maternal cpDNA inheriatnce for $C$. konishii, but this remains to be verified.

Occurrence of the same ancestral haplotype could be an indication of the same origin shared by populations because no sharing was found for those newly derived haplotypes in C. konishii. The following reasoning can be used to explain why there is no sharing of rare haplotypes found within $C$. konishii, and between C. konishii and C. lanceolata. First, the appearance of most de novo haplotypes was only very recent. Second, the newly developed alleles will have slow rate of dispersion because long regeneration time might limit the generation number to 20 since last glaciation. Because $C$. konishii is a long-life plant, $1-2 \mathrm{~m}$ in diameter is common in old-growth forest that was estimated to be more than 1000 years old. Moreover, high humidity growth environment limit the dispersion of pollen and seeds.

\section{Inferences of demographic history of C. konishii}

Taiwan would have been connected with Asian landmass by a landbridge when sea levels decreased during glacial stages (Liu 1988). This landbridge would have enhanced the gene flow of many species including Cunninghamia. The track of gene flow between two Cunninghamia species can be seen from the mingled genealogical relationships of two $C$. lanceolata haplotypes LGD2 and LJS4 to five C. konishii haplotypes, KKW1, KTJ1, KYH4, KWL2 and KTJ2, as depicted in the TCs haplotype network (Fig. 2a). However, gene flow of Cunninghamia from China to Taiwan during Holocene would be very rare or unlikely to occur, thus resulting in the independent evolution of de novo evolved rare cpDNA alleles.

The distributions of the haplotypes in C. konishii are uninformative in suggesting a clearcut postglacial migration pattern. This may indicate either that population and individual sampling was too limited to detect a postglacial migration pattern, or that C. konishii has spread from different cryptic glacial refugia within the Central Mountain Ridge, a lofty mountain range from north to south in the middle of island. On the other hand, altitudinal migration of species during glacial / interglacial extremes was suggested (Hewitt 1996). Although Taiwan had never been glaciated, the temperature was $8.0-11.0^{\circ} \mathrm{C}$ cooler compared to the present-day temperature, as determined from one lake core in an altitude of $745.5 \mathrm{~m}$ in central Taiwan (Tsukada 1966). It is probable that during Pleistocene glaciation $C$. konishii migrated to lower altitude and recolonized the higher altitude during interglacial periods.

The 'star-like' phylogeny of haplotypes indicates positive selection or a population bottleneck in the historical demography of C. konishii (Nordborg \& Innan 2002). Occurrence of a single, common, and often frequent ancestral 
haplotype in all populations suggests population bottleneck event in red pine (Echt et al. 1998) and that may also be what has happened in C. konishii. The presence of excess rare alleles together with unimodal mismatch distribution, and significantly negative Tajima's $D$ and Fu \& Li's $D^{*}$ indicated recent population expansion in C. konishii (Fig. 2; Table 1, Aris-Brosou \& Excoffier 1996). The inference of population expansion may be supported further by the following reasoning. Growth of conifers may be strongly influenced by factors such as slope steepness, edaphic factors and humidity, as well as competition with other species. Consequently, decline in temperature in the lower elevation did not necessarily provide a suitable environment for the growth of C. konishii. A remarkably high value of herbs (Poaceae) indicates a dry environment according to fossil pollen records from Toushe (650 $\mathrm{m}$ high) and JihTan (750 m high) in central Taiwan (Liew \& Chung 2001) during glaciation. In contrast, fluctuation in vegetational gain and loss during 10000 and 47000 BP in C. konishii was found and indicates recurrent population bottleneck and expansion in this species according to pollen analysis by Tsukada (1967). This dry climate prevailing is clearly a serious limiting factor in restraining C. konishii to several cryptic refugial habitats during glacial maximum. Because C. konishii survived only in cool temperatures with a high humidity climate, a dry environment would create a serious bottleneck effect with the result that only ancestral, the most common haplotype, survived after the glaciation.

The present study revealed some interesting similarities, but also discrepancies, with the study by Lu et al. (2001). The similarities are, first, that taxic difference is minimal between $C$. konishii and C. lanceolata based on chloroplast DNA variation; second, cpDNA nucleotide diversity tends to be higher within populations of $C$. konishii than within C. lanceolata populations; third, chloroplast DNA variation revealed no geographical structure. However, geographical structure was detected in some occasions ( $\mathrm{Lu}$ et al. 2001). The total number of individuals and populations examined are higher in our study. The limited number of populations analysed in Lu et al. (2001) could lead to a biased inference of migration history of Cunninghamia from mainland China to Taiwan as cautioned by Templeton (1998). We found low nucleotide diversity in four chloroplast DNA fragments in contrast to the high nucleotide diversity of only one cpDNA fragment reported in Lu et al. (2001). Low nucleotide diversity was also found for several plant species in Taiwan, which grow in different altitudinal range, but may have experienced common geological history, including Cyclobalanopsis glauca (Huang et al. 2002), Machilus thunbergii (Hwang et al. unpubl. data), Castanopsis carlesii and Trochodendron aralioides (Lin et al. unpubl. data) from fieldcollected samples. A well-structured phylogenetic tree was found in Lu et al. (2001); however, our result indicated a star-like chloroplast DNA phylogeny. Our inference of the demographic history of C. konishii is supported by fossil pollen evidence (Tsukada 1967; Liew \& Chung 2001). These differences suggest that further studies on the evolution and phylogeography of Cunninghamia in Taiwan are warranted.

\section{Acknowledgements}

This project was funded by the National Science Council (grant nos NSC 89-2313-B-034-013 and NSC 90-2313-B-034-008), Executive Yuan, Taiwan. We would like to express our sincere gratitude toward Mr Ji-Shen Wu, Division of Silviculture, Taiwan Forest Research Institute, for his kind help in sample collections.

\section{References}

Aris-Brosou S, Excoffier L (1996) The impact of population expansion and mutation rate heterogeneity on DNA sequence polymorphism. Molecular Biology and Evolution, 13, 494-504.

Bucci G, Vendramin GG (2000) Delineation of genetic zones in the European Norway spruce natural range: preliminary evidence. Molecular Ecology, 9, 923-934.

Chen YW, Shi JS (1983) Some fundamental problems in the genetic improvement of Chinese fir. Journal of Nanjing Institute of Forestry, 4, 1-21.

Chiang TY, Chiang YC, Chen YJ et al. (2001) Phylogeography of Kandelia candel in East Asiatic mangroves based on nucleotide variation of chloroplast and mitochondrial DNAs. Molecular Ecology, 10, 2697-2710.

Cruzan MB, Templeton AR (2000) Paleoecology and coalescence: phylogeographic analysis of hypotheses from the fossil record. Trends in Ecology and Evolution, 15, 491-496.

Demesure B, Sodzi N, Petit RJ (1995) A set of universal primers for amplification of polymorphic noncoding regions of mitochondrial and chloroplast DNA in plants. Molecular Ecology, 4, 129-131.

Doyle JJ, Doyle JL (1987) A rapid DNA isolation procedure for small quantities of fresh leaf material. Phytochemistry Bulletin, 19, 11-15.

Dumolin-Lapègue S, Demesure B, Fineschi S, Lecorre V, Petit RJ (1997) Phylogeographic structure of white oaks throughout the European continent. Genetics, 146, 1475-1487.

Echt CS, DeVerno LL, Anzidei M, Vendramin GG (1998) Chloroplast microsatellites reveal population genetic diversity in red pine, Pinus resinosa Ait. Molecular Ecology, 7, 307-316.

Ferris C, Oliver RP, Davy AJ, Hewitt GM (1995) Using chloroplast DNA to trace postglacial migration routes of oaks into Britain. Molecular Ecology, 4, 731-738.

Fu YX, Li WH (1993) Statistical tests of neutrality of mutations. Genetics, 133, 693-709.

Hamrick JL, Godt MJW, Sherman-Broyles SL (1992) Factors influencing levels of genetic diversity in woody plant species. In: Population Genetics of Forest Trees. Proceedings of the International Symposium on Population Genetics for Trees (eds Adams WT, Strauss S, Copes D, Griffin AR), pp. 95-124. Kluwer Academic Publishers, the Netherlands.

Harpending H (1994) Signature of ancient population growth in a low resolution mitochondrial DNA mismatch distribution. Human Biology, 66, 591-600. 
Hewitt GM (1996) Some genetic consequences of ice ages, and their role in divergence and speciation. Biological Journal of the Linnean Society, 58, 247-276.

Huang SSF, Hwang SY, Lin TP (2002) Spatial pattern of chloroplast DNA variation of Cyclobalanopsis glauca in Taiwan and East Asia. Molecular Ecology, 11, 2349-2358.

Hwang LH, Hwang SY, Lin TP (2000) Low chloroplast DNA variation and population differentiation of Chamaecyparis formosensis and Chamaecyparis taiwanensis. Taiwan Journal of Forest Science, 15, 229-236.

Hwang SY, Lin HW, Kuo YS, Lin TP (2001) RAPD variation in relation to population differentiation of Chamaecyparis formosensis and Chamaecyparis taiwanensis. Botanical Bulletin of Academia Sinica, 42, 173-179.

Liew PM, Chung NJ (2001) Vertical migration of forests during the last glacial period in subtropical Taiwan. Western Pacific Earth Sciences, 1, 405-414.

Lin TP, Wang CT, Yang JC (1998) Comparison of genetic diversity between Cunninghamia konishii and C. lanceolata. Journal of Heredity, $89,370-373$.

Liu T (1966) Study on the phytogeography of the conifers and taxads of Taiwan. Bulletin of the Taiwan Forest Research Institute, No. 122.

Liu KB (1988) Quaternary history of the temperate forest of China. Quaternary Science Review, 7, 1-20.

Lu SY, Peng CI, Cheng YP, Hong KH, Chiang TY (2001) Chloroplast phylogeography of Cunninghamia konishii (Cupressaceae), an endemic conifer of Taiwan. Genome, 44, 797-807.

Matyas G, Sperisen C (2001) Chloroplast DNA polymorphism provide evidence for postglacial re-colonisation of oaks (Quercus spp.) across the Swiss Alps. Theoretical and Applied Genetics, 102, 12-20.

Müller-Starck G, Liu YQ (1989) Genetics of Cunninghamia lanceolata Hook. 2. Genetic variation within and between two provenance samples. Silvae Genetica, 38, 172-177.

Nei M (1987) Molecular Evolutionary Genetics. Columbia University Press, New York

Nordborg M, Innan H (2002) Molecular population genetics. Current Opinion in Plant Biology, 5, 69-73.

Otto SP (2000) Detecting the form of selection from DNA sequence data. Trends in Genetics, 16, 526-529.

Palmer JD (1987) Chloroplast systematics: uses of chloroplast DNA variation. American Naturalist, 130, S6-S29.

Palmer JD, Jans en RK, Michaels HJ, Chase MW, Manhart JR (1988) Chloroplast DNA variation and plant phylogeny. Annals of the Missouri Botanical Garden, 75, 1180-1206.

Pons O, Petit RJ (1996) Measuring and testing genetic differentiation with ordered versus unordered alleles. Genetics, 144, 12371245.

Ribeiro MM, Mariette S, Vendramin GG, Szmidt AE, Plomion C, Kremer A (2002) Comparison of genetic diversity estimates within and among populations of maritime pine using chloroplast simple-sequence repeat and amplified fragment length polymorphism data. Molecular Ecology, 11, 869-877.

Richardson BA, Brunsfeld SJ, Klopfenstein NB (2002) DNA from bird-dispersed seed and wind-disseminated pollen provides insights into postglacial colonization and population genetic structure of whitebark pine (Pinus albicaulis). Molecular Ecology, 11, 215-227.

Rogers AR, Harpending HC (1992) Population growth makes waves in the distribution of pairwise genetic differences. Molecular Biology and Evolution, 9, 552-569.

Rozas J, Rozas R (1999) DNASP, version 3: an integrated program for molecular population genetics and molecular evolution analysis. Bioinformatics, 15, 174-175.

Taberlet P, Gielly L, Pautou G, Bouvet J (1991) Universal primers for amplification of three non-coding regions of chloroplast DNA. Plant Molecular Biology, 17, 1105-1109.

Tajima F (1989) Statistical method for testing the neutral mutation hypothesis by DNA polymorphism. Genetics, 123, 585-595.

Templeton AR (1998) Nested clade analysis of phylogeographic data: testing hypotheses about gene flow and population history. Molecular Ecology, 7, 381-397.

Templeton AR, Crandall KA, Sing CF (1992) A cladistic analysis of phenotypic associations with haplotypes inferred from restriction endonuclease mapping and DNA sequence data. III. Cladogram estimation. Genetics, 132, 619-633.

Thompson JD, Higgins DG, Gibon TJ (1994) CLUstaL w: improving the sensitivity of progressive multiple sequence alignment through sequence weighting, position-specific gap penalties and weight matrix choice. Nucleic Acids Research, 22, 4673-4680.

Tsukada M (1966) Late Pleistocene vegetation and climate in Taiwan (Formosa). Proceedings of the National Academy of Sciences USA, 55, 543-548.

Tsukada M (1967) Vegetation in subtropical Formosa during the Pleistocene glaciation and the Holocene. Palaeogeography, Palaeoclimatology, Palaeoecology, 3, 49-64.

Vendramin GG, Anzidei M, Madaghiele A, Sperisen C, Bucci G (2000) Chloroplast microsatellite analysis reveals the presence of population subdivision in Norway spruce (Picea abies K.). Genome, 43, 68-78.

Vendramin GG, Degen B, Petit RJ, Anzidei M, Madaghiele A, Ziegenhagen B (1999) High level of variation at Abies alba chloroplast microsatellite loci in Europe. Molecular Ecology, 8, 1117-1126.

Yeh FC, Shi J, Yang R, Hong J, Ye Z (1994) Genetic diversity and multilocus associations in Cunninghamia lanceolata (Lamb.) Hook from the People's Republic of China. Theoretical and Applied Genetics, 88, 465-471.

The authors collaborate on projects on population dynamics of angiosperm and gymnosperm species using molecular markers including AFLP, organelle and nuclear DNA sequences in Taiwan, which is not glaciated. Shih-Ying Hwang, Chiu-Shun Ma and ChungLing Lin conduct research on the evolutionary genetics of conifers and other organisms. Tsan-Piao Lin has been working on the population genetics and phylogeography of many native plant species of Taiwan. Jeng-Der Chung and Jenq-Chuan Yang have interest in the breeding and conservation of Cunninghamia konishii. 